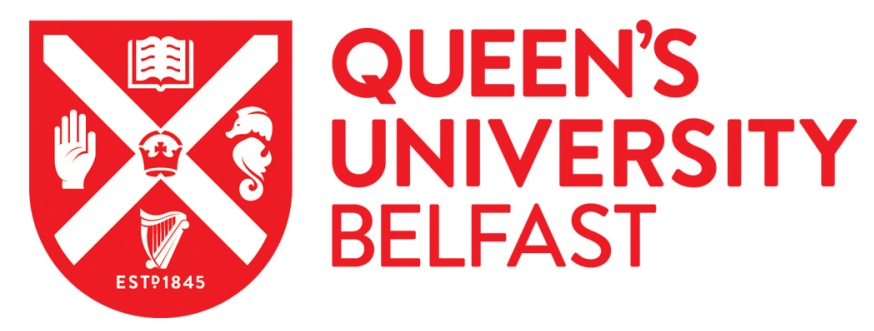

\title{
Smartphone chronic gaming consumption and positive coping practice
}

de Kervenoel , R., Schwob, A., Palmer, M., \& Simmons, G. (2017). Smartphone chronic gaming consumption and positive coping practice. Information Technology and People, 30 (2), 503-519. https://doi.org/10.1108/ITP01-2016-0003

Published in:

Information Technology and People

Document Version:

Peer reviewed version

Queen's University Belfast - Research Portal:

Link to publication record in Queen's University Belfast Research Portal

Publisher rights

(c) 2016 Emerald Group Publishing.

This work is made available online in accordance with the publisher's policies. Please refer to any applicable terms of use of the publisher.

\section{General rights}

Copyright for the publications made accessible via the Queen's University Belfast Research Portal is retained by the author(s) and / or other copyright owners and it is a condition of accessing these publications that users recognise and abide by the legal requirements associated with these rights.

Take down policy

The Research Portal is Queen's institutional repository that provides access to Queen's research output. Every effort has been made to ensure that content in the Research Portal does not infringe any person's rights, or applicable UK laws. If you discover content in the Research Portal that you believe breaches copyright or violates any law, please contact openaccess@qub.ac.uk. 


\title{
Smartphone chronic gaming consumption and positive coping practice
}

\begin{abstract}
:
Purpose - Chronic consumption practice has been greatly accelerated by mobile, interactive and smartphone gaming technology devices. This study explores how chronic consumption of smartphone gaming produces positive coping practice. Design/methodology/approach - Underpinned by cognitive framing theory, empirical insights from eleven focus groups $(n=62)$ reveal how smartphone gaming enhances positive coping amongst gamers and non-gamers.

Findings - The findings reveal how the chronic consumption of games allows technology to act with privileged agency that resolves tensions between individuals and collectives. Consumption narratives of smartphone games, even when play is limited, lead to the identification of three cognitive frames through which positive coping processes operate: (a) the market generated frame, (b) the social being frame, and (c) the citizen frame.
\end{abstract}

Research limitations/implications - This paper adds to previous research by providing an understanding of positive coping practice in the smartphone chronic gaming consumption.

Originality/value - In smartphone chronic gaming consumption, cognitive frames enable positive coping by fostering appraisal capacities in which individuals confront, hegemony, culture and alterity-morality concerns.

Keywords: Digital Transformation, Smartphone Gaming, Positive Coping, Chronic Consumption, Frames

Paper type: Research paper

\section{Introduction}

This research explores how smartphone chronic gaming consumption produces positive coping practice. There is an increasing body of conceptual and empirical work that considers how information technology shapes consumption (Alexander and Sackett, 2013; Ashton, 2011; Chulmo et al., 2015; Watts and Wyner, 2011). This work has drawn attention to the temporal, relating most closely to notions of clock 
time (Lin et al, 2015), for example, in the enhancement of waiting times for services. It has also highlighted the role of the temporary, as a bounded occurrence with a start and end point (Aggarwal and Vaidyanathan, 2003), for example, Cyber Monday or Black Friday. However, these time-based consumption activities have been impacted by transformation of digital technologies and, as a consequence, the speeding up of social life. Digital transformation is defined as "the realignment of, or new investment in, technology and business models to more effectively engage digital customers at every touch point in the customer experience lifecycle” (Forbe, 2014).

As such, digital transformation has re-set many of the norms associated with temporal and temporary understandings of consumption practice. For instance, the storage and distribution of digital content (e.g. music, online videos, live video streams, e-books etc.) as well as the development of new devices have resulted in direct and instant access to online consumption activity. Within digital transformation, consumption is no longer bound or restricted to the traditional ideas of temporal and temporary consumption cycles found in repeat purchased situations, such as daily, weekly or monthly. Instead, a myriad of frequent hourly encounters and indeed irregular temporal encounters (e.g. during the night) are occurring that can be termed chronic consumption. Whereas some studies support the view that digital transformation processes have produced positive impacts, creating back office and frontline efficiencies as well as creating consumption opportunities (Ling and Campbell, 2011; Van Belleghem, 2015); others point to the stresses arising from a digital environment where technological demands challenge individuals' traditional frames of reference, stability and resources, thereby threatening consumption (Addis, 2005; Chulmo et al., 2015; Hansson, 2015; Rosa, 2003).

Within the context of digital transformation, the term 'mobile culture' reflects the influence that digital devices and their services have on the temporal acceleration of day-to-day activities (Gane, 2006; Hjorth and Richardson, 2010; Readhead, 2004). For example, reports suggest the average UK user interacts with their phone more than 1,500 times in one week: expending three hours and sixteen minutes a day (Daily Mail, 2014). While many studies have explored technologies in relation to technological culture, they have emphasized the negative effects of such transformation in terms of a loss of privacy, or loss of humanity. Most current views on digital transformation do not recognise the value of social acceleration -the speeding up of social life - particularly how this pertains to chronic smartphone 
consumption and to the associated demands of living in a knowledge society (Zwick and Dholakia, 2006).

Alongside the traditional modes of smartphone communication (e.g. talk, texting, Internet), smartphones are providing access to novel gaming consumption behaviours that are fast, easy and fun - for example, the Angry Birds Model- (Van Belleghem, 2015). Such games represent a particularly popular form of smartphone content consumed representing approximately 1.82 billion gamers and estimated to reach a market value of $\$ 102.9$ billion by 2017 (Newzoo, 2014). The cultural history of mobile gaming has a broad reach (Shaw, 2010; Gordon and de Souza e Silva, 2011). Smartphone gaming institutionalization, trends and related institutions are visible in areas such as: policy regulation (de Kervenoael et al., 2013); education (McClarty et al., 2012); organizational strategy (Klasnja and Pratt, 2012); egovernment (Burroughs, 2014), and edutainment (Hjorth, 2010). Despite such insights, it is argued that there is a relative absence of discussions of the people side of technology, and in particular, the 'play impulse' dimension at the root of all culture (Huizinga, (1955 [1938]). This research therefore starts to inform, in part, our overall research question of how smartphone gaming may represent a form of coping with the uncertainty of digital transformation (de Souza da Silva and Hjort, 2009; Juul, 2010; Richardson, 2011). Viewing smartphone gaming as a form of chronic consumption in this way raises further important research questions and are examined in more detail below.

We advance the argument that smartphone gaming is a form of chronic consumption which produces an agency to resolve tensions between individuals and collectives. In this respect, the smartphone gaming agency produces positive coping, moving away from the mitigation of issues towards an aggregation of experiences, allowing individuals to cognitively frame, hedge risk and pragmatically accept digital transformative uncertainties. Towards that end, the overall aim of this paper is to investigate the links between smartphone gaming as a form of chronic consumption and positive coping practice. Specific objectives are: (1) to identify how individuals frame, draw on and leverage smartphone gaming as a form of chronic consumption to cope with social uncertainty caused by digital transformation; (2) to identify forms of positive coping practice occurring through smartphone gaming, whether individuals are gamers or non-gamers. The paper proceeds as follows. Theoretical insights are outlined on the context in which smartphone consumption and coping occur together 
with how frames are leveraged. We then introduce the adopted methodology. In the third part, we present the findings before discussing contributions to existing research.

\section{Theoretical Background}

\section{The digital transformation of society and coping processes}

"Any attempt to make sense of the human condition at the start of the new century must begin with the analysis of the social experience of speed” (Scheuerman, 2004: 1). Acceleration or speed is a constitutive trait of modernity (Mick and Fournier, 1998; Tomlinson, 2007). The speeding up of social life is evident not only in the social domains such as hi-tempo electronic dance music (Attias et al., 2013), or descriptions of generation X (Coupland, 1996; Wajcman, 2014), but also in the commercial domains with the introduction of new products as well as built-in product obsolescence. Digital transformation has been central to this acceleration. For example, according to a recent Forrester (2015) report, smartphone owners in OECD countries renew their devices every year on average. Product replacement acceleration becomes even more severe when built-in obsolescence limits the life cycle of devices as confirmed by a recent study (Sacco, 2013). Key characteristics and conditions of digital transformation include mobility, real time and location aware consumption, networked and ubiquitous access to various devices and platforms (e.g. smartphone, tablets, I-Store), constant interactions (e.g. reviews, likes, feedbacks), and the blurring of public and private spaces as well as work-life balance and multitasking (Cousins and Robey, 2015).

Research studies on the consumption of digital technological artefacts have attempted to provide insights into this digital transformation and to understand how individuals are located within techno-temporal structures. Research shows how individuals are connected with 'others'; making it virtually impossible to be outside the digital network (Magaudda, 2011). The constant network attachment and connection to digital technologies has changed the time-based consumption activities. In turn, moral judgments are made on how smartphones are used, and with specific forms of chronic consumption patterns emerging that deviate from prescribed (i.e. what individuals should do) and proscribed (i.e. what is the normative order). One related characteristic of this phenomenon is the way that smartphone gaming lacks "real life" stability allowing magical objects and powers to be used within universes where being the hero or villain are both sought after. Studies show that this may lead 
to new psychological and emotional connections and attachments (separate from traditional addiction) but also forge (quasi) social relations that allow users 'to cope' with the uncertainty of digital transformation (Knorr-Cetina, 2001; Schiller, 2007).

Traditionally, research focusing on technology consumption has been concerned with issues including antecedents, transaction rates, and act of technology adoption (Schilling, 2010). Coping in that sense reflects the Information Systems perspective which is primarily concerned with technology ease of use and appropriation of features representing coping with machines (Bijker and Law, 1992), or in comparison to consumption of a more physical kind (e.g. Belk, 2013; DenegriKnott and Molesworth, 2012). Here, coping is portrayed in term of positive efficiency gains, information and access inclusion. Implications pertaining to instituting of routines and rituals, or the instantiation of identity and consumption per se are then drawn (Kozinets, 2008; Mick and Fournier, 1998).

From another perspective, Duhachek (2005) interprets coping as an effort to manage and overcome demands of critical events using a set of procedures that answer a threat (see also Lazarus, 2000; Lopez et al., 2011). Several studies suggest that coping is context-dependent (Lazarus and Folkman 1984) and reflects different levels of complexity, appraisal and maturity. More generally, the work of Lazarus (2000) identifies two types of appraisal in coping processes. Primary appraisals are where the individual evaluates and gives personal meaning to events and considers the significance of 'what is at stake', in terms of harm, threat or challenge. 'Secondary appraisal' further refines the meaning surrounding the event and addresses the question, 'What can I do about it?' This is where the individual evaluates the availability of coping resources to deal with the appraisal of harm, threat or challenge (Lazarus 2000). Next to the previous view, psychology-based studies have shown the existence of various forms of mental coping (e.g. reaching out for support, nonjudgmental behaviors and positive reading), physical coping (e.g. deep breathing, meditation and stretching), emotional coping (e.g. listening to music, group therapy, retail therapy) and spiritual coping (e.g. praying, volunteering and mindfulness to others). Positive coping can thus take various forms that involve relationships with others and often technics or technological devices.

Smartphone gaming as one form of chronic consumption requires an understanding of how individuals cope with the uncertainty of accelerating digital transformation. Essentially, coping in the context of technology has both 
directionality and normative duration but the specifics are blurry (Feijoo et al., 2012; Shaw, 2010). Accordingly, existing knowledge about the social function of smartphone games as a form of chronic consumption splits between research stressing dysfunctionality (e.g. anti-social behavior, dangerous practices, psychological disorders addiction) and positivity (e.g. effective communications collaboration strategies - oral textual and manual dexterity, construction of identity collaborative problem-solving literacy practices and systematic thinking) (Ducheneaut and Moore, 2004; Gee, 2003; Steinkuehler, 2006).

Coping positively with technological uncertainty (see Lipchitz and Strauss, 1997 for a review of the concept of uncertainty) via smartphone gaming may even threaten to unravel individual and collective behaviours (Arnould and Thompson, 2005), as gaming chronic consumption represents overt manifestations of individual coping (Benford et al., 2003). Smartphone games, encompassing virtual and actual, online and offline, haptic and visual, delay and immediacy, provide individuals with new skills and knowledge. Facilitated by the freemium model, apps-based social games have flipped traditional roles, whereby “casual gamers” led an evolution often leveraging the urban environment and digital media with physical activities and faceto-face social interaction. Taken together, in the chronic consumption of smartphone games, positive coping merges the traditional social function of coping with political collective negotiations opportunities offered by the digital transformation project. Nonetheless, positive coping manifestations as they appear reflectively and positively to the individual have not been properly investigated.

\section{Technological framing applied to chronic smartphone consumption}

The literature on smartphones has used the notion of frame and enframing, whereby technology is not only physical but conceptual (Berthon et al., 2005; Gal and Berente, 2008; Kidd, 2011). We interpret framing as widely used in research related to technological frames in organizations, along with the ambiguities and paradoxes that technologies imply (Barrett at al., 2013; Goffman, 1974; Leonardi, 2011; Mazmanian, 2013; Orlikowski and Gash, 1994; Van Burg et al., 2013). That is to say, culturally different individuals share a common technology and are empowered to interpret a turbulent world and take actions, while at the same time, having scope for dissonance and situational improvisation. Thus, different groups such as smartphone gamers and non-gamers can share strong similarities despite evidencing clear differences in 
adoption, preferences and strategies for action (Cornelissen and Werner, 2014; Swidler, 1986). Consumption enables individuals and groups to be reflexive about social practices and what appears as digital demands emanating from marketers, other consumers, and other stakeholders. This reflexivity can be a primed or activated cognitive frame based on knowledge represented in the frame with limited adaptability. These practices and demands are constantly examined and reformed in the light of their perceived effective instantiation (frame-based meanings constructed in context and reflecting new ways of thinking about individuals' environment) (Benner and Tripsas, 2012; Kaplan, 2008;).

So far in consumer research, framing approaches follow two main avenues: the formative associative network structure to describe consumers' knowledge of products (Lawson, 1998), and the purposeful effort from certain actors to influence others in developing trajectories (Humphreys and Latour, 2013). Work on the 'granularization' of technological frames (separating a frame problem into subcomponents and underlying the role of ambiguity) also reveals framing as a tool that enables exchange between user groups (Vaccaro et al., 2011). In other words, the concept(s) of frames may be used to explain why groups of individuals sharing access to the same toolkit of cultural resources might act differently when interacting with the same technology. Framing becomes an ongoing interpretative process beyond detailing consequences and moving from "naming frames to studying framing process analytically” (Benford, 1997: 423). So, it is in interaction with others that individual relevance is recognised and collective meaning agreed between various types of users (Giddens, 1984; Kaplan, 2008).

Taken together, the acceleration or speeding up of social life is both a performative and reflective dimension of digital transformation. The literature on coping processes as well as framing offers a theoretically rich way of understanding smartphone gaming as a form of chronic consumption and the agency for resolving tensions between individuals and collectives. In summary, then, coping forms are articulated in the individual's mobilizations of complementary and intertwined cognitive frames through which they develop expression and appraisal capacities to cope with digital transformation uncertainties. The methods we used to explore this further are detailed in the next section of the paper.

\section{Methodology}


In this paper we aimed to explore the links between smartphone gaming as a form of chronic consumption and positive coping practice. An abductive approach was adopted (Dubois and Gadde, 2002), which borrows from the systematic combining efforts of the researcher as a constant move "between asking questions, generating hypothesis and making comparisons” (Dubois and Gadde, 2002). In line with abductive reasoning, the study combined several types of data including: different aspects of smartphone gaming consumption (e.g. practices, anecdotes, meanings); segmentation along smartphone experiences and a contextualizing review of the mainstream UK press for secondary topical material.

Focus groups emerged as an appropriate method given the overall study aim and objectives, as the socio-cultural phenomena and the form of coping could evolve as the outcome of a collective negotiation that was likely to be reflected in the focus groups. "Focus groups [. . .] are not simply a means of interviewing several people [...] but rather are concerned to explore the formation and negotiation of accounts within a group context, and to see how people define, discuss and contest issues through social interaction” (Seale, 2004: 194). The cognitive frames and how these served the coping phenomenon, were facilitated by the moderator's observation in the data collection process of a laddering method (i.e. starting by querying the meaning of the obvious taken-for-granted) and probing for differences among respondents (i.e. pointing out contradictions) to provide a critique in interpretation (i.e. critical creative unveiling).

The study employed a total of eleven digitally recorded focus groups ( $n=62)$, further split into six male and five female groups reflecting the gendering of digital games (see Table 1) (Caronia, 2005; Rommes, 2002; Shade, 2008). Individual owning phones but who had never played games were excluded. The age division followed on from previous research reporting that interest in mobile games is higher in age groups 15-24 (one group female non-adopters 23-28, could not be recruited; only 2 respondents were aged 9 years old) (Flurry, 2011, ISG, 2012; Nokia, 2002). Parental agreement was obtained before the interviews with minors and a confidentiality agreement was given to all participants, along with a short description of the study, following the researchers' institutional ethical guidelines. We chose not to conduct discussions between gamers and non-gamers, considering that what mattered was to investigate forms of coping that primarily required an individual to deal with the market and not with issues such as the symbolic meanings of games. Themes 
investigated in the focus groups included: definitions of key terms (smartphone gaming, online social culture, network, value creation, tension among stakeholders unpacking of actors) and self-defined roles/usages of a smartphone in a respondent's lifestyle; the meaning and purpose of smartphone gaming (non)consumption in relation to engagement with the technological artefact within social environments in both private and public situations; identification of practices that did, or did not, represent prescribed or desired practices by smartphone marketers.

\begin{tabular}{|l|c|c|c|c|l|}
\hline \multirow{2}{*}{ N=62 } & \multicolumn{2}{|c|}{ Male } & \multicolumn{2}{c|}{ Female } & \\
\cline { 2 - 5 } Age 9-15=22 & User & Non-user & User & Non-User & Duration: Average time 90 minutes \\
Age 16-22= 23 & 5 & 5 & 6 & 6 & Location: London, UK \\
Age 23-28=17 & 6 & 6 & 5 & 6 & Timing: HTML 5, Ipad2, iPhone 4 \\
\hline \\
User: individual who plays games regularly and who frequently purchases or downloads new games \\
Non-User: individual who owns a smartphone but only consumes pre-loaded, factory-set games (not \\
downloaded free or charged games from third party providers
\end{tabular}

Table 1: Participants distribution in the eleven focus groups

Emergent themes in the data (researcher's observations) were compared with the construct of frame as understood from the literature. The importance of what we identified as a given frame was assessed regarding the tangible and intangible resources or reference point (i.e. a given type of stakeholder, or an ideology) it mobilized for the respondents. This process of isolation of cognitive frames followed the common broader process of qualitative data analysis including activities related to categorization, abstraction, comparison, dimensionalization, integration, and iteration (Spiggle, 1994). Finally a consensus was sought among researchers about the existence of three overarching intertwined frames that structured consumers' narratives.

\section{Findings}

The underlying dynamic uncovered from this study was that gamers and non-gamers developed individual reactions to the ongoing flow of expressed vs. latent digital transformation demands of smartphone gaming. This constituted positive coping with associated uncertainties amplified within an accelerated culture. Relationship to smartphone gaming enabled the individual to "secure" in his/her mind, novel forms of understanding and actions regarding the marketplace and about embeddedness as a 
consumer within the marketplace, but also as an individual within broader culture and collectives.

Coping forms were articulated in the individual's mobilizations of three complementary and intertwined cognitive frames through which they could develop expression and appraisal capacities to confront and improvise with hegemony, culture, and moral concerns / alterity. These three objects of confrontations are organized in what we have respectively called the "market-generated", the "social being” and the "citizen" frames. Digital chronic consumption "activated" frames in individual minds. Each respondent tended indirectly to make frames robust by encountering their limitations, which in turn allowed collective redefinition of frames. They engaged in questioning when inherent paradoxes or contradictions arose from the exclusive reliance on a given frame. Through frames, individuals strengthened their socio-cultural understanding and meanings of smartphone gaming as a form of chronic consumption. The relative fluidity by which each individual manoeuvred across the culture through frames suggests that coping implies positive outcomes for the individual sense of self. This positive valence is related to the fact that individuals appreciated those interactions with various kinds of stakeholders and related cultural resources that actually "mattered" to them. Figure 1 below summarizes the main findings around these key points.

Figure 1: Positive coping with digital technology

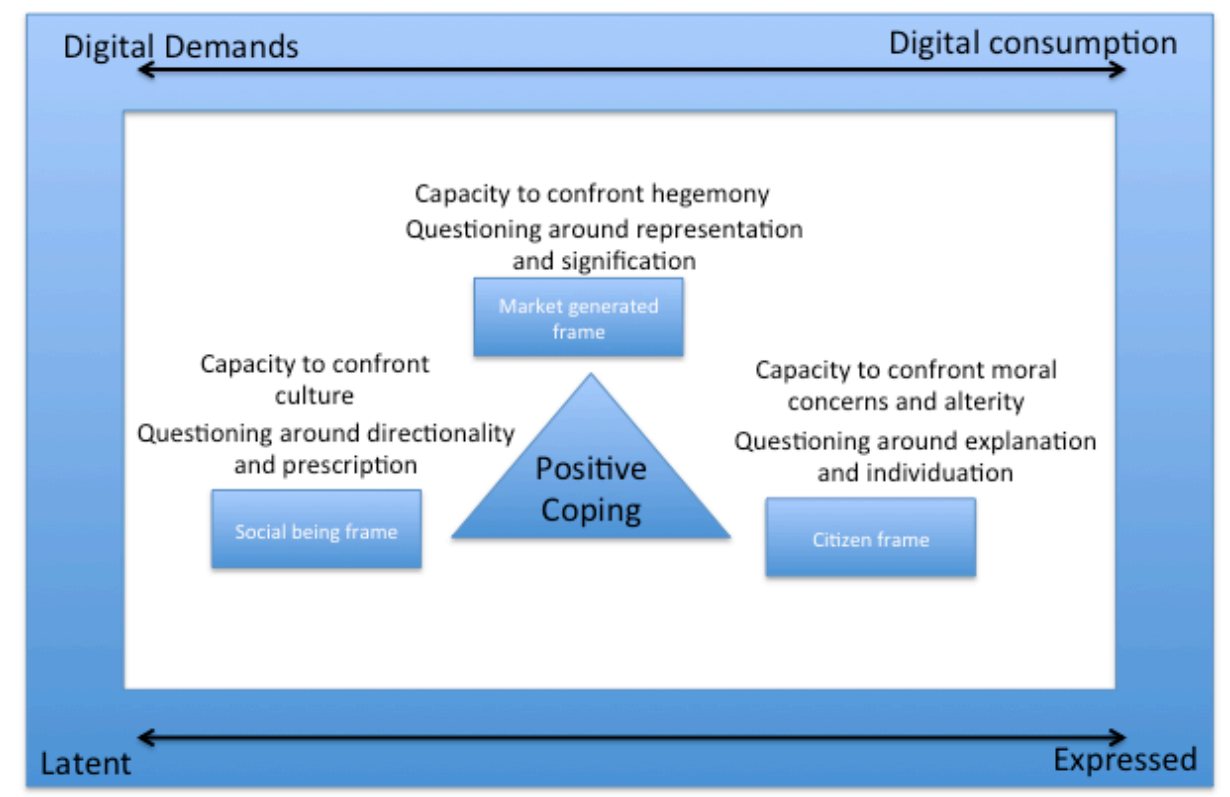


The market generated frame: revealing the hegemonic power of marketplace resources and their downside

Respondents whether they were smartphone gamers or non-gamers, revealed a frame associated with the subject position of being a consumer that relied on brands, producers and market generated materials to evaluate trustworthy relationships. One respondent illustrated the relevance in individuals' minds of being a consumer in order to deal with this.

[one respondent to another] Few games are dominating the official market (Itune, android equivalent). We all have at least one version of them. I am tracking tricks to move between level and access accessories earlier and only share with friends that deserve it. (Male, gamer, 16-22)

These standpoints impacted upon how smartphone gaming was chronicallyconsumed across time and enabled to track the value creation process. This 'market generated' frame, implied that the respondents positioned themselves as consumers facing value propositions emanating from firms. The responses revealed that they appeared to confront the hegemony of the latter, while also questioning their relationships with a diffused set of marketplace entities beyond the most popular smartphone games' brands. With freemium games, the respondents' interactions revealed that the issue of consumption started well before the classic and static purchase of branded products. It should be acknowledged that this chronic consumption was also fostered by over half of non-gamers who defined games within a broader category (e.g. selfies, download of other applications) when articulating the meanings of mobile technology consumption in their lived experiences. As such, the signification of brands and of commoditized artifacts (i.e. what these really represent) was expressed.

There are many other things you can do besides gaming. Lots of apps for everything and tonnes of new ones each day [...]. Some are good some are terrible, some I cannot understand. Games have a lot of competition with applications that are also entertaining and fun. 
These are more adapted to my lifestyle may be more grown up too.

(Female, non-gamer, 16-22)

Thus, the smartphone games market allowed respondents to engage in primary forms of coping by understanding that digital chronic consumption is not just a matter of brands, images, signs and meanings, but also represent technology origin, social speed, ethical and political foci. Under the market-generated frame, gamers appeared to be critical towards technology because its commodification was viewed as problematic. A dominant view emerging from the data indicated that cognition triggered a readiness to be critical about what they could really do with mobile technology consumption in a way that assuaged their needs whilst questioning the meaning of the market generated frame. Non-gamers extended digital transformation meaning so that their knowledge structure fitted with social acceleration (emerging fads on new media, new brands etc.). For instance, one of the respondents, a nongamer, revealed how the dynamic of value acknowledgment and destruction was framed by a reliance on marketplace positions, and showed that the market generated frame allowed him to give credit to firms' brands and technological device configurations in order to initiate symbolic self-projects.

[one respondent to another] This is my phone, state of art, totally cool. It is factory pre-set. But with this phone you are not the same as somebody else. I have play station and Wii if I want to play games. Mobile games are boring, I already completed the one on it, 50 levels took a couple of hours. They are too expensive for what they do, graphics are small and not worth it. Better get a good one on PS3...may be new games will be more suited for that phone soon (Male, non-mobile-gamer, 9-15)

The analysis of the data also indicated that the market-generated frame was sustained by the re-integration of firms' information (marketing) in view of future technology chronic consumption. For any given individual the consumption processes of various digital devices and games appeared to be overlapping, thus, underlying the necessity but at the same time very often the current lack in practice of games' definition and interoperability across platforms. This coping form therefore provides 
macro-viewpoints of the brandscape following the development of capacities to confront other stakeholders over time.

The social being frame: expressing one's need for embeddedness

In this frame the respondents elaborated further on their association to the wider environment surrounding smartphone games and related technologies (such as headphones, or phone covers, fashion, expression, imaginary magical artefacts) consumption. With what we have termed the social being frame, individuals were better equipped to express and appraise their need for embeddedness regarding their presence next to others while chronically consuming.

It is really easy on a smartphone to have cool stuff. It says you are up to date. It also allows me to show off a bit with my gaming friends and with the effects produced when I am on the Tube! (laughs) (Male, gamer, 16-22)

Or

'[one participant to another] We exchange games quite often, I buy one you buy one and via Bluetooth, it is free. We compete against each other and I think it is fair to say that I get to stamp a bit of me and my ideas on the group through sharing the sort of more thoughtful games I prefer' (Male, gamer, 9-15)

An identity was evident through which needs appeared to be fulfilled and value was consumed. This invited the respondents to add "qualities” and personalize the use of technologies they encountered. We argue that this cognitive work predominantly illustrates an individual ability to confront culture. It is of major importance since it informs the multifaceted nature of social interactions and the potential negotiation of norms (what digital transformation prescribe) among individuals. This subtle and dynamic form of coping with technology occurred within a network that could be both insecure and unknown (generally free) or official and generally paid for. It led to respondents questioning what technology as a whole prescribes or how it could be used in a way that could sustain social relations negatively or positively with those virtually rather than physically present. The social- 
being frame encourages previous theories of technology consumption to include 'others' that paradoxically also shape consumption from "the outside”. This cognitive work goes in tandem with the phenomenon of contournement and amplification of technologies, as illustrated in the following quote.

Most games are only for one player. I like games where you need a team like on PS3 but on mobile it is not yet that advanced and many people do not know or want to play multi-players games. Good multiplayer games are hard to find. It will be nice to be able to share with whoever is with you rapidly without all that login. Are photo effects a game because I do that a lot with friends? (Female, gamer, 16-22)

Under this frame, respondents also took different stances and subject positions in a kind of 'play' mode; allowing them to develop affective disposition and sensibilities towards their gaming chronic consumption practices. When this frame was salient, respondents' often used humor to reflect on themselves and their digital possessions consumption.

In mobile games it is ok to get killed or stop in the middle. You can even play back the crash and share it with your friends. You often have to lose in any case as you have to move quickly to another activity or you get bored knowing what is coming. (Female, gamer, 915)

This enactment took different forms of sensing towards the close environment in the course of their experiences; a dominant view emerging from the respondents reported they had been relaxed, stressed, irritated, avoiding or seeking social contact. As one of the respondents revealed, consumers can take part in different experiences; demonstrating how conventional marketing discourse has shifted by focusing on the importance of the collective.

I have Bluetooth, so I get a lot from my stepson. I am happy as it is free and he can show me. He has tested them for me and knows my 
tastes. Peer to peer is the best system for games. (Female, gamer, 23-

The citizen frame: scrutinizing the general interest

Being driven by goals, shaped by marketplace influences and the collective gaze, respondents' view of individuality was challenged; leading them in turn to renegotiate the discursive consumption architectures and forms of coping offered by digital technology. This frame provides initial evidence that smartphone gaming as a form of chronic consumption facilitated preferences such as cultural tastes and ways to connect with others that were expressed and re-negotiated.

I am not a huge fan of video games in general. I do have a few that came with the phone. Playing does not make you individual anymore.

You are individual if you do not have games. I am protecting myself

against wasting time. I think people with game are just trying to attract attention. (Male, non-gamer, 23-28)

Questioning of technological value appeared to be primarily made possible through more or less radical problematization, in which suitable usages of digital games were reflected upon. These linked to what we have termed the citizen frame, with judgmental views on smartphone games around a cognitive frame that allowed the respondents to take into account the possibility of others' views in order to stay attuned with perceived higher-order technological necessities.

It is all about what the others are doing with their phone and games. New trends are created every day. You see that with video clips. New groups are created with their own demands and needs. The type of game and where they come from is getting larger. (Male, gamer, 1622)

The citizen frame was especially salient when the respondents revealed common groupings through which gaming technologies were collectively used highlighting acceptable ways to play games in public spaces: essentially, 'all is 
permitted'. Smartphone gaming had legitimate priority, including permanent visibility and authorization to multitask. Under the citizen frame, the respondents understood their role when consuming technology, but also were able to go beyond marketers' strategies to assume that a general interest and a more authentic sense of individuality could be reached.

I have a Blackberry, this is a serious phone, got it for work, I do not expect many to carry games and I don't think the business types who use these phones would approve of gaming on them in the middle of a serious Board meeting for example (laughs). (Female, non-gamer, 1622).

So, through smartphone gaming as a form of chronic consumption, the fulfillment of individual goals by respondents did not necessarily require to recognize fully the technical possibilities of specific devices. However, this also raises issues of potential identification and recognition errors, and creates potential tensions with respect to social etiquette wherein every smartphone owner is equivalent to any other. This was discussed in the focus groups around game encounters that required, as part of the play, making identification in real life (IRL) a relevant concern. Indeed, the type of device and its specific followers via the mediation of approved meeting points were viewed as a means to segregate or engage with passersby. In doing so, gamers and non-gamers came to clarify their positive coping trajectories for a general interest. They developed different interactional styles (place, time, game connection with public settings etc). This attempt to reach unification was situated within the respondents' minds and called for a citizen frame that comprehended and integrated altruistic concerns for others.

Taken together, the three frames can be described as a pair of glasses that individuals use to interpret the turbulent world of digital transformation and take action (see Figure 1). The findings suggest that this interpretation and enabled actions are not just corrective; they rather enable positive coping practices. Frames structure narratives, and by doing so they enable individuals to "secure” and undertake novel forms of understanding and actions regarding their embeddedness as a consumer within the marketplace, but also regarding their individuality within broader culture and collectives. The frames reveal that games on Smartphones have become 
crystallized as a set of social and material relations providing scope for dissonance and situational improvisation. Frames 'work for' and are 'worked on' by a host of individuals, ideologies, philosophies, principles and other social and material elements becoming an ongoing interpretative process that provides a basis to understand how individuals are located within techno structures and how they cope. Whether individuals see playing games on Smartphones as enabling and empowering or as disruptive, deskilling and controlling, their reliance on cognitive frames within their narratives shows that their interactions with Smartphones enables them to act within an ambiguous and rapidly evolving technological ecosystem.

The three frames, market generated (as capacity to confront hegemony), social being (as capacity to confront culture) and citizen (as capacity to confront moral concerns and alterity) articulate the nature of coping from individual to collective interpretations. The gaming process is presented as conflicted and often misinterpreted by certain actors, but this triggers a need to shift between the frames. Through appraisal capacities developed by individuals employing the three frames, the findings show that positive coping processes emerge. The enhancement of frames and of positive coping processes is enabled through connection between the frames and through the different confrontations and questioning each frame represents. The findings especially shows how, by relying on the same set of frames as gamers, nongamers do matter and shape - indirectly but positively - Smartphone gamers' behaviours to achieve broader social goals. Moreover, the findings explore in a more explicit fashion where the consumption boundaries of Smartphone gamers and nongamers converge, disappear, or are redefined outside of a firms' control. While most previous research has disregarded the importance of external socio-cultural conditions in coping mechanisms, the findings suggest that cultural reframing of technological artefacts is motivated by representations of social interactions and by the negotiation of the ascribed rules or assumptions of use promoted by Smartphone manufacturers and retailers. Beneath the three frames, the findings also bring evidence on secondorder and more subtle forms of cultural re-framing -such as rejection, postponement, and opposition.

\section{Discussion}

In this paper we have sought to explore how smartphone gaming as a form of chronic consumption mitigated digital transformation uncertainty in an accelerated culture. 
We extend in doing so previous research by demonstrating that positive coping is evident in the respondents' consumption narratives. Even though existing knowledge indicates that technologies serve continuous learning, knowledge development and often positive outcomes that serve individuals' sense of self (Addis, 2005; Kozinets, 2015), it does not focus on how coping operates in the realm of (convergent) chronic consumption of mobile technologies (Petruzzellis, 2010). By focusing on how smartphone game consumption' narratives produce novel positive coping processes, this study builds and provides new insights regarding digital transformation together with emerging positive coping forms. Leveraging the three frames (market generated, social being and citizen frames), the study findings identify congruent chronic consumption behaviours related to digital transformation and digital services including gaming by both smartphone gamers and non-gamers. This consumption multiplicity is found to facilitate continuous learning and knowledge development, increasing the artefact's complexity over time, but also allowing emerging coping forms operationalized via three main frames. Furthermore, the majority of respondents were expecting the 'others' (smartphone gamers or non-gamers depending on starting point) to engage in the on-going learning process. Describing their playing activities (for gamers) or merely referring to game-like activities on smartphones was enabling and empowering, refining the meaning of technology transformation.

Smartphone games are presented as privileged actors that facilitated emergent norms among the study respondents. We argue that this reveals in turn that cultural trends operate within the uncertainty of digital transformation by including a balancing viewpoint to smartphone gaming that has been termed disruptive, deskilling, polluting the social environment and potentially controlling (Kozinets, 2008). One particular area of theoretical insight in our findings is the role of un-organised, peripheral, non-strategic, non-institutionalised actors as catalysts in the (re)framing of digital transformation, underlining the interdependencies of knowledgeable agents in shaping its societal impact. We explicitly identify where the consumption boundaries of smartphone gamers and non-gamers converge or are redefined outside the control of the marketers' of smartphone games (de Kervenoael et al., 2015). The role of noninstitutionalized 'others' is essential, not least because such actors sit on the boundaries of two fields and thus experience tension/ clash of institutionalized expectations. Most of the studies on digital transformation consumption are often 
portrayed as "either marginal or as only one element in the wider social-accelerative process" (Hassan, 2010: 361), while others present digital technologies as representing “a new social morphology ... [with a] logic [that] substantially modifies the operation and outcomes in processes of production, experience, power and culture” (Castells, 1996: 469). Significant from the findings of this study is the necessity to further problematize how technology-related consumption not only produces iterative and market-led feature redesigns, through user-generated content, or value co-creating practices, but how the social interaction in, through and behind gaming activity also produces more nuanced changes of smartphone games' initial intents or designs.

Through the cognitive framing of convergent technologies, in this study smartphone gaming as a form of chronic consumption is shown to facilitate positive coping with digital transformation uncertainties. Prioritising consumption reframing practices over marketers' prescriptions posits consumer power not as negative or confrontational, but as a (co)creative force, structuring fields of interaction and exchange of free agents (Denegri-Knott et al., 2006). Research on coping is multidisciplinary and as a socio-technical phenomenon it takes evolving forms, yet a noticeable shortcoming in the literature is the lack of consideration of the effects on coping of the rise of post-social relations within chronic consumption (Knorr Cettina, 2001) and overall digital technology transformation (Zwick and Dholakia, 2006). On the one hand, consumer culture researchers have shown the importance of consumption dynamics for individual coping strategies in various contexts (Pavia and Mason, 2004; Sujan et al., 1999), but they have remained quiet in their empirical consideration about technology's potential to serve the coping agenda. This study attempts to bridge this gap by acknowledging the implications of the technologization of society in terms of coping. We isolate the role that convergent mobile gaming technology chronic consumption plays in coping. Referring to the context of smartphone gaming, the findings show how chronic-gaming enables individuals to cope positively with uncertainties that persistently problematize the link between individuals and the collective (Berthon, 2005).

\section{Conclusion}

Coping mechanisms are built in narratives that articulate the three frames and that allow individuals to develop capacities to face hegemony, culture, and alterity-moral 
concerns. A given frame enables to engage in the questioning of the inherent paradoxes or contradictions that arise from the reliance on other frames. Each frame draws the attention of individuals on questions of representation and signification (market generated frame), directionality and prescription (social being frame) and/or explanation and individualization (citizen frame) activating positive coping mechanisms.

Our research calls for re-organisation of relationships and collaboration between technologists and digital consumers but does not fully reject current marketing approaches (Green et al, 2001). As such, it is important to re-visit the classical assumptions within the gaming industry underlying a lack of socio-cultural understanding of gaming that can be considered as a manifestation of chronic consumption on Smartphone and other mobile devices. For example, most game retailers may too often base their strategy on past data, which means that they may not understand fully the lack of console-based (PS3, Nintendo) gaming heritage evident for most mobile game users. In a similar area, most marketing and communication related to smartphone games seem to be mainly directed at long standing smartphone gamers. In essence, we question whether there is not a shortcoming that classify individuals who play Farmville and Angry Birds as "gamers" in the same sense as those who play Starcraft and Call of Duty. Ultimately, regarding games per se, minigames built for touchscreen devices are now dominating the app market and they are often based on freemium models. Is the socio-cultural understanding and practices of chronic mobile game sufficiently attentive to the behavioural aspects generated by the presence of free and charged services?

Drawing on the above game examples, our three frames foster the creation of new strategic chronic consumption forms congruent with consumers at whatever stage of the consumption cycle they are at; creating both greater scope for existing digital technologies and more inclusive societal understanding of future technological artefacts and services (Matthing et al., 2004). As found in the press review (articles published about the issue in the generic English press) of this study, selection and execution of gaming opportunities are indicated as key issues. From an industry perspective, the exponential growth in GPS-based games provides evidence of rapid adaptation of the market to digital transformation opportunities. Consider, for example, 'Tourality' and 'Waymarking' as games where a number of locations are chosen for each game in order to build a community map of cool places (Hjorth, 
2010). A different example relates to wearable digital technology or the internet of things that records personal information (e.g. blood pressure, sugar level) and allows owners to monitor themselves and to control daily activities remotely. A noncommercial example includes Cancer Research UK which has launched free smartphone games in which players help scientists to find patterns in genetic data from cancer patients (Play to Cure: Genes in Space). As a result, the challenge for marketing around digital technology chronic consumption is how to build capabilities that can relate to individual consumers without infringing on the community: i.e. the stimulation of consumer embeddedness within digital transformation.

\section{References}

Addis, M. (2005), "New technologies and cultural consumption - edutainment is born!”, European Journal of Marketing, Vol. 39 Nos. 7/8, pp. 729-736.

Alexander, D.L., Sackett, A.M. (2013), "If only I had the time! The impact of time salience on consumers' evaluations of product offers”, Journal of Consumer Behaviour, Vol. 12 No. 5, pp. 382-388.

Aggarwal, P, and Vaidyanathan, R. (2003), "Use it or lose it: Purchase acceleration effects of time-limited promotions", Journal of Consumer Behaviour, Vol. 2 No. 4, pp. 393-403.

Arnould, E. J. and Thompson, C. J. (2005), “Consumer culture theory (CCT): Twenty years of research”, Journal of Consumer Research Vol. 31 No. 4, pp. 868-882.

Ashton, D. (2011), "Playstations and workstations: identifying and negotiating digital games work", Information Technology \& People, Vol. 24 No. 1, pp. 10 - 25.

Attias, B., Gavanas, A. and Rietveld, H. (2013), DJ Culture in the Mix, Power, Technology, and Social Change in Electronic Dance Music, Bloomsbury Academic.

Barrett, M., Heracleous, L. and Walsham, G. (2013), “A rhetorical approach to IT diffusion: Reconceptualizing the ideology-framing relationship in computerization movements”, MIS Quarterly, Vol. 37 No. 1, pp. 201-220.

Belk, R.W. (2013), "Extended self in a digital world", Journal of Consumer Research, Vol. 40 No. 3, pp. 477-500.

Benford, R.D. (1997), “An insider's critique of the social movement framing perspective”, Sociological Inquiry Vol. 67 pp. 409-30.

Benford, S., Anastasi, R., Flintham, M., Drozd, A., Crabtree, A. and Greenhalgh, C. (2003), "Coping with uncertainty in a location-based game", IEEE Pervasive Computing, Vol. 2 No. 3, pp. 34-41.

Benner, M. J. and Tripsas, M. (2012), "The influence of prior industry affiliation on framing in nascent industries: the evolution of digital cameras", Strategic Management Journal, Vol. 33 No. 3, pp. 277-302.

Berthon, P., Hulbert, J. M. and Pitt, L. (2005), "Consuming technology: Why marketers sometimes get it wrong”, California Management Review, Vol. 88 No. 1, pp. 110-128.

Bijker, W.E. and Law, J. (1992), Shaping technology / Building society, Cambridge, MA: MIT Press. 
Burroughs, B. (2014), "Facebook and FarmVille: A digital ritual analysis of social gaming”, Games and Culture, Vol. 9 No. 3, pp. 151-166.

Caronia, L. (2005), "Mobile culture: An ethnography of cellular phone uses in teenagers' everyday life”, Convergence, Vol. 11 No. 3, pp. 97-103.

Castells, M. (1996), The Rise of the Network Society, The Information Age: Economy, Society and Culture, Vol. I. Cambridge, MA; Oxford, UK: Blackwell.

Chulmo, K., Chung, N., and Kim, H-W. (2015), "Examining explorative and exploitative uses of smartphones: a user competence perspective”, Information Technology \& People, Vol. 28 No. 1, pp.133-162.

Cornelissen, J. P. and Werner, M. D. (2014), "Putting framing in perspective: a review of framing and frame analysis across the management and organizational literature", The Academy of Management Annals, Vol. 8 No.1, pp. 181-235.

Coupland, D. (1996), Generation X: Tales for an Accelerated Culture, New York: St Martin Press.

Cousins, K. and Robey, D. (2015), "Managing work-life boundaries with mobile technologies", Information Technology \& People, Vol. 28 No. 1, pp. 34-71.

Daily Mail, (2014), "How often do YOU look at your phone?" http://www.dailymail.co.uk/sciencetech/article-2783677/How-YOU-lookphone-The-average-user-picks-device-1-500-times-day.html\#ixzz3rCHXdzkf

De Kervenoael, R., Bisson, C., and Palmer, M. (2015), "Dissidents with an innovation cause? Non-institutionalized actors' online social knowledge sharing, solution-finding tensions and technology management innovation" Information Technology \& People, Vol. 28 No. 3, pp. 653-676.

De Kervenoael, R., Palmer, M., and Hallsworth, A. (2013), "From the outside in: Consumer anti-choice and policy implications in the mobile gaming market", Telecommunication Policy, Vol.37 Nos.6/7, pp. 439-449.

Denegri-Knott, J., and Molesworth, M. (2012), "Concepts and practices of digital virtual consumption”, Consumption Markets \& Culture, Vol.13 No.2, pp. 109132.

Denegri-Knott, J., Zwick, D., and Schroeder, J. E. (2006), "Mapping consumer power: an integrative framework for marketing and consumer research", European Journal of Marketing, Vol. 40, Nos. 9/10, pp. 950-971.

De Souza da Silva and Hjort, L. (2009), "Playful urban spaces: A historical approach to mobile games”, Simulation \& Gaming, Vol. 40 No. 5, pp. 602-625.

Dubois, A. and Gadde, L. E. (2002), "Systematic combining: an abductive approach to case research", Journal of Business Research, Vol. 55 No. 7, pp. 553-560.

Ducheneaut, N., and Moore, R. J. (2004), "The social side of gaming: a study of interaction patterns in a massively multiplayer online game”, In Proceedings of the ACM conference on computer-supported cooperative work (pp. 360369), November 6-10, Chicago IL, USA, NY: ACM.

Duhachek, A. (2005), "Coping: A multidimensional, hierarchical framework of responses to stressful consumption episodes", Journal of Consumer Research, Vol. 32 No.1, pp. 41-53.

Feijoo, C., Gómez-Barroso, J. L., Aguado, J. M., and Ramos, S. (2012), "Mobile gaming: industry challenges and policy implications", Telecommunications Policy, Vol. 36 No. 3, pp. 212-221.

Flurry.com (2011), "Flurry Blog, Mobile gamers: the new mass-market powerhouse" Feb 22. /http://blog.flurry.com/bid/57219/Mobile-Social-Gamers- 
Forbe, (2014), “Digital transformation by any other name?" http://www.forbes.com/sites/jasonbloomberg/2014/07/31/digitaltransformation-by-any-other-name/

Forrester (2015), "Forrester Research world mobile and smartphone adoption forecast, 2015 to 2020".

https://www.forrester.com/report/Forrester+Research+World+Mobile+And+S martphone+Adoption+Forecast+2015+To+2020+Global/-/E-RES127942

Gal, U. and Berente, N. (2008),"A social representations perspective on information Mailsystems implementation", Information Technology \& People, Vol. 21 No. 2 pp. $133-154$.

Gane, N. (2006), "Speed up or slow down? Social theory in the information age", Information, Communication and Society, Vol. 9 No. 1, pp. 20-38.

Gee, J. P. (2003), What video games have to teach us about learning and literacy. New York: Palgrave.

Giddens, A. (1984), The constitution of society: Outline of the theory of structuration. University of California Press

Goffman, E. (1974), Frame analysis: an essay on the organization of experience, Harper and Row, New York.

Gordon, E. and de Souza e Silva, A. (2011), Net locality, London, UK: WileyBlackwell

Green, N. Harper, R.H.R. Murtagh, G. and Cooper, G. (2001), "Configuring the mobile user: sociological and industry views", Personal and Ubiquitous Computing, Vol. 5 No. 2, pp. 146-156.

Hansson, N. (2015), "Mobility-things and consumption: conceptualizing differently mobile families on the move with recent purchases in urban space", Consumption Markets \& Culture, Vol. 18 No. 1, pp. 72-91.

Hassan, R. (2010), "Social acceleration and the network effect: a defence of social 'science fiction' and network determinism”, The British Journal of Sociology, Vol.61 No. 2, pp. 356-74.

Hjorth, L. (2010), Games \& Gaming. London: Berg.

Hjorth, L., and Richardson, I. (2010), "The waiting game: Complicating notions of (tele)presence and gendered distraction in casual mobile gaming”. In Cultures of participation, ed. H. Greif, L. Hjorth, A. Lasen, and C. Lobet-Maris, pp. 111-25. New York: Peter Lang.

Humphreys, A. and Latour K. (2013), "Framing the game: Assessing the impact of cultural representations on consumer perceptions of legitimacy," Journal of Consumer Research, Vol. 40 No. 4, pp. 773-795.

Huizinga, J. (1955), Homo Ludens: A Study of the Play-element in Culture, Beacon Press.

Information Solution Group (ISG) (2012), “2012 POPCAP game mobile gaming research” http://www.infosolutionsgroup.com/popcapmobile2012.pdfS.

Juul, J. (2010), A casual revolution: Reinventing video games and their players. Cambridge, MA: MIT Press.

Kaplan, S. (2008), "Framing contests: Strategy making under uncertainty", Organization Science, Vol. 19 No. 5, pp. 729-752.

Kidd, J. (2011), "Enacting engagement online: framing social media use for the museum", Information Technology \& People, Vol. 24 No. 1 pp. 64 - 77.

Klasnja, P. and Pratt, W. (2012), "Healthcare in the pocket: Mapping the space of mobile-phone health interventions", Journal of Biomedical Informatics Vol. 45, No. 1, pp. 184-198. 
Knorr-Cetina, K. (2001), "Postsocial relations: Theorizing sociality in a postsocial environment”, in Ritzer, G. and Smart, B. (eds), Handbook of Social Theory. London: Sage, pp. 520-537.

Kozinets, R.V. (2008), “Technology/ideology: How ideological fields influence consumers' technology narratives.” Journal of Consumer Research, Vol.34 No. 6, pp. 864-881.

Kozinets, R.V. (2015), Netnography: redefined, Sage: London.

Lawson R. (1998),"Consumer knowledge structures: networks and frames", in NA Advances in Consumer Research, eds. Joseph W. Alba \& J. Wesley Hutchinson, Provo, UT: Association for Consumer Research, Vol. 25 No. 1, pp. 334-340.

Lazarus, R. S. (2000), "Toward better research on stress and coping," American Psychologist, Vol. 55 No. 6, pp. 665-673.

Leonardi, P. M. (2011), "Innovation blindness: Culture, frames, and cross-boundary problem construction in the development of new technology concepts", Organization Science, Vol. 22 No. 2, pp. 347-369.

Lipchitz, R. and Strauss, O. (1997), "Coping with uncertainty: a naturalistic decisionmaking analysis”, Organizational Behavior and Human Decision Processes Vol. 69 No. 2, pp. 149-163.

Ling, R., and Campbell, S.W. (Eds.) (2011), Mobile communication: Bringing us together and tearing us apart. New Brunswick, NJ: Transaction Publishers

Lin, Y.-T., Xia, K.-N., Bei, L.T., (2015), "Customer's perceived value of waiting time for service events”, Journal of Consumer Behaviour, Vol. 14 No. 1, pp. 28-40.

Lopez, S. J., Snyder, C. R. and Teramoto Pedrotti, J. (2011), Positive psychology: The scientific and practical explorations of human strengths, London: Sage.

Magaudda, P. (2011), “When materiality 'bites back': Digital music consumption practices in the age of dematerialization”, Journal of Consumer Culture, Vol. 11 No.1, pp.15-36.

Matthing, J. Sanden, B. and Edvardsson, B. (2004), “New service development: learning from and with customers”, International Journal of Service Industry Management, Vol. 15 No. 5, pp. 479-498.

Mazmanian, M. (2013), “Avoiding the trap of constant connectivity: When congruent frames allow for heterogeneous practices”, Academy of Management Journal, Vol. 56 No. 5, pp. 1225-1250.

McClarty, K.L, Orr, A., Frey, P.M., Dolan, R.P., Vassileva, V. and McVay, A. (2012) "A literature review of gaming in education", http://researchnetwork.pearson.com/wpcontent/uploads/Lit_Review_of_Gaming_in_Education.pdf

Mick, D.G. and Fournier, S. (1998), "Paradoxes of technology: Consumer cognizance, emotions, and coping strategies”, Journal of Consumer Research, Vol. 25 No. 2, pp. 123-147.

Newzoo, (2014), "Global games market will reach \$102.9 billion in 2017" http://www.newzoo.com/insights/global-games-market-will-reach-102-9billion-2017-2/

Nokia, (2002), "Mobile terminal software-markets and technologies for the future", http://nds2.ir.nokia.com/NOKIA_COM_1/About_Nokia/Press/

Orlikowski, W. J. and Gash, D. C. (1994), "Technological frames: making sense of information technology in organizations”, ACM Transactions on Information Systems, Vol. 12 No. 2, pp. 174-208. 
Pavia, T. and Mason, M. (2004), "The Reflexive Relationship between consumer behavior and adaptive coping", The Journal of Consumer Research Vol. 31 No. 2, pp. 441-454.

Petruzzellis, L. (2010), “Mobile phone choice: technology versus marketing. The brand effect on the Italian market”, European Journal of Marketing, Vol. 44 No 5, pp. 610-634.

Readhead, S. (2004), Paul Virilio: Theorist for an accelerated culture. University of Toronto Press.

Richardson, I. (2011), “The hybrid ontology of mobile gaming”, Convergence: The International Journal of Research into New Media Technologies, Vol. 17 No. 4, pp. 419-430.

Rommes, E. (2002), Gender scripts and the internet: The design and use of Amsterdam's digital city, Enschede: Twente University Press.

Rosa, H. (2003), "Social acceleration: Ethical and political consequences of a desynchronized high-speed society”, Constellations, Vol.10 No.1, pp. 3-33.

Sacco, A. (2013), "Evolution of the Smartphone refresh cycle, planned obsolescence and you", http://www.cio.com/article/2380720/hardware/evolution-of-thesmartphone-refresh-cycle--planned-obsolescence-and-you.html

Scheuerman, W. (2004), Liberal democracy and the social acceleration of Time, Johns Hopkins University Press, Baltimore, MD.

Schiller, D. (2007), How to think about information, Urbana: University of Illinois Press.

Schilling, M.A. (2010), Strategic management of technological innovation, $3^{\text {rd }}$ Edition Boston: McGraw Hill.

Seale, C. (2004), Researching Society and Culture, 2nd ed. Thousand Oaks, CA and London: Sage Publication.

Shade, L.R. (2008), "Feminizing the mobile: Gender scripting of mobiles in North America”, Goggin, G. Ed., Mobile Phone Culture, London: Routledge, pp. 4252.

Shaw, A. (2010), "What is video game culture? Cultural studies and game studies", Games and Culture Vol. 5 No. 4, pp. 403-424

Spiggle, S. (1994), Analysis and interpretation of qualitative data in consumer research, Journal of Consumer Research, Vol. 21, No. 3, pp. 491-503.

Steinkuehler, C. A. (2006), "Why game (culture) studies now?”, Games and Culture, Vol. 1 No. 1, pp.1-6.

Sujan, M., Sujan H., Bettman J., and Verhallen T. (1999), "Sources of consumers' stress and their coping strategies," European Advances in Consumer Research, Vol. 4, pp. 182-187.

Swidler, A. (1986), "Culture in action: Symbols and strategies", American Sociological Review, Vol. 51 No. 2, pp. 273-286.

Tomlinson, J. (2007), The culture of speed: The coming of immediacy, Los Angeles, Sage.

Vaccaro, A., Brusoni, S., and Veloso, F. M. (2011), "Virtual design, problem framing, and innovation: An empirical study in the automotive industry," Journal of Management Studies, Vol. 48 No. 1, 99-122.

Van Belleghem, S. (2015), When digital becomes human, Kogan Page: London.

Van Burg, E., Berends, H., and van Raaij, E.M. (2013), "Framing and interorganizational knowledge transfer: A process study of collaborative innovation in the aircraft industry”, Journal of Management Studies, Vol. 1 No.3, pp. 349-378. 
Wajcman, J. (2014), Pressed for time: The acceleration of life in digital capitalism, University of Chicago Press Books.

Watts, S. and Wyner, G. (2011), "Designing and theorizing the adoption of mobile technology mediated ethical consumption tools”, Information Technology \& People, Vol. 24 No. 3 pp. 257 - 280.

Zwick, D. and Dholakia, N. (2006), "The epistemic consumption object and postsocial consumption: Expanding consumer-object theory in consumer research”, Culture, Markets, and Consumption, Vol.9 No.1, pp. 17-43. 